\title{
Toll-Like Receptor Mediated Modulation of T Cell Response by Commensal Intestinal Microbiota as a Trigger for Autoimmune Arthritis
}

\author{
Rebecca Rogier, Marije I. Koenders, and Shahla Abdollahi-Roodsaz \\ Experimental Rheumatology, Radboud University Medical Center, 6500 HB Nijmegen, Netherlands \\ Correspondence should be addressed to Shahla Abdollahi-Roodsaz; shahla.abdollahi-roodsaz@radboudumc.nl
}

Received 18 July 2014; Accepted 23 September 2014

Academic Editor: David B. Ordiz

Copyright (c) 2015 Rebecca Rogier et al. This is an open access article distributed under the Creative Commons Attribution License, which permits unrestricted use, distribution, and reproduction in any medium, provided the original work is properly cited.

\begin{abstract}
In autoimmune diseases, a disturbance of the balance between T helper 17 (Th17) and regulatory T cells (Tregs) is often observed. This disturbed balance is also the case in rheumatoid arthritis (RA). Genetic predisposition to RA confers the presence of several polymorphisms mainly regulating activation of T lymphocytes. However, the presence of susceptibility factors is neither necessary nor sufficient to explain the disease development, emphasizing the importance of environmental factors. Multiple studies have shown that commensal gut microbiota is of great influence on immune homeostasis and can trigger the development of autoimmune diseases by favoring induction of Th17 cells over Tregs. However the mechanism by which intestinal microbiota influences the Th cell balance is not completely understood. Here we review the current evidence supporting the involvement of commensal intestinal microbiota in rheumatoid arthritis, along with a potential role of Toll-like receptors (TLRs) in modulating the relevant Th cell responses to trigger autoimmunity. A better understanding of TLR triggering by intestinal microbiota and subsequent T cell activation might offer new perspectives for manipulating the T cell response in RA patients and may lead to the discovery of new therapeutic targets or even preventive measures.
\end{abstract}

\section{Introduction}

Rheumatoid arthritis (RA) is a systemic autoimmune disease, which is characterized by chronic inflammation and progressive cartilage and bone destruction in multiple joints. A world-wide prevalence of about $1 \%$ ranks RA among the most-common autoimmune disorders [1]. Current therapy of RA is based on a choice, or often a combination, of nonsteroidal anti-inflammatory drugs (NSAIDs), diseasemodifying antirheumatic drugs (DMARDs), glucocorticoids, and recently the so-called Biologicals targeting specific cytokines or certain immune cells.

The etiopathology of RA is complex, because cells of the innate and adaptive immune system as well as joint resident cells such as fibroblasts and chondrocytes contribute to the development and progression of RA [2]. The production of proinflammatory cytokines such as tumor necrosis factor (TNF) $\alpha$ and interleukin (IL)-1 and activation of lymphocytes are considered to play important roles in RA pathogenesis
$[3,4]$. A specific subset of T cells, known as T helper 17 (Th17) cells, is considered to be a major pathogenic mediator in RA $[3,5,6]$.

Although the exact etiology remains unclear to date, RA is generally considered a multifactorial disease in which both genetic and environmental factors play a role [7]. Epidemiological studies have revealed that the largest genetic risk factors for RA are certain alleles of the HLA-DR gene [8]. In addition, polymorphisms in protein tyrosine phosphatase N22 (PTPN22), peptidyl arginine deiminase type IV (PADI4), signal transducer and activator of transcription 4 (STAT4), and TNF receptor-associated factor $1 /$ complement C5 (TRAF1/C5) were found associated with RA [8]. However, the presence of susceptibility factors is neither necessary nor sufficient to explain the disease development, underlining a critical role for environmental factors.

Meta-analysis has shown that smoking is one of the environmental factors associated with RA pathogenesis [9]. In addition to smoking, periodontal pathogens such as 


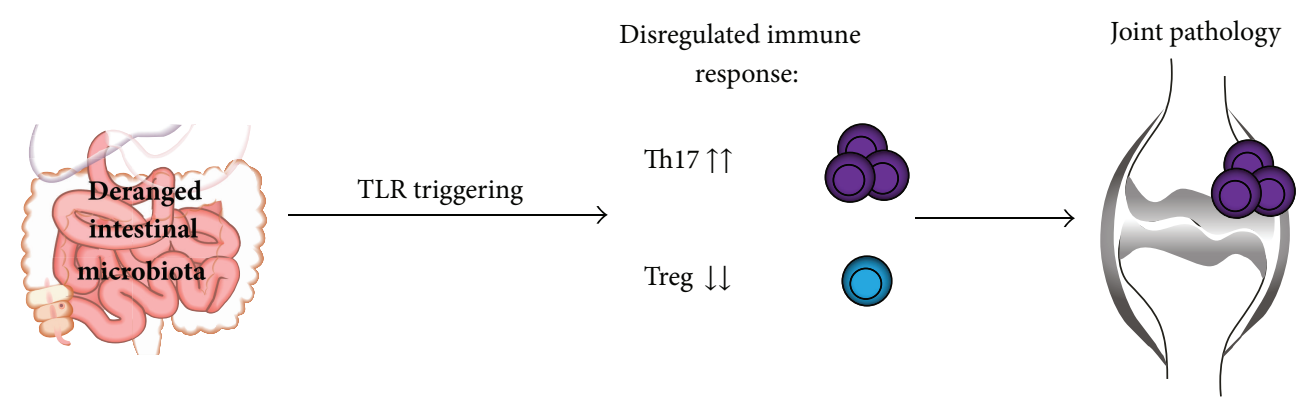

FIGURE 1: Exposure to deranged intestinal microbiota or a disregulated immune response to microbiota drives rheumatoid arthritis by promoting Th17 and deranging Treg cells.

Porphyromonas gingivalis and the induced periodontal disease have been implicated in the etiology of RA $[10,11]$. Besides infectious bacteria, commensal bacteria have been implicated in the pathogenesis of RA [12]. In addition, there is strong evidence that Toll-like receptors (TLRs), which recognize microbial products, contribute to RA progression [13-15].

Most of the polymorphisms associated with RA are involved in regulating $\mathrm{T}$ cell activation [16]. The genetically altered $\mathrm{T}$ cells are potentially autoreactive, that is, they may react to self-antigens in the joint and cause autoimmunity; nevertheless, the "naïve" $\mathrm{T}$ cells (called Th0) first need to become activated and acquire a pathogenic phenotype in order to be harmful. Exposure to (deranged) intestinal microbiota may be a critical factor. The aim of this review is to discuss the role of intestinal bacteria in the development of $\mathrm{RA}$ in the context of $\mathrm{T}$ cell modulation and the possible role that TLRs play in this process (Figure 1).

\section{Th17 Cells and Rheumatoid Arthritis}

Th17 cells protect against bacterial and fungal infections; however they also promote the development of autoimmune diseases such as multiple sclerosis, inflammatory bowel disease, psoriasis, and RA [17-22]. Regulatory T cells (Tregs) downregulate inflammation and serve to prevent tissue damage and autoimmunity. The balance between Th17 cells and Tregs is strictly regulated, and imbalance is thought to promote autoimmunity [23]. In RA, increased percentages of Th17 cells have been found in peripheral blood mononuclear cells (PBMCs) of patients [22]. These Th17 cells were shown to be potent inducers of matrix metalloproteinases and proinflammatory cytokines upon interaction with synovial fibroblast, thereby contributing to joint damage [22].

Other studies found increased levels of Th17 cells and decreased levels of Tregs in peripheral blood of patients with active RA [24, 25]. Furthermore, RA patients have Tregs with decreased suppressive activity [26]. Transforming growth factor (TGF) $\beta$ is a key factor involved in maintaining the Th17/Treg cell balance: TGF $\beta$ in combination with IL-6 or IL21 promotes Th17 differentiation, but when TGF $\beta$ is present in combination with IL-2, it will induce differentiation of Tregs [27, 28]. Inhibition of IL-6 function was shown to correct the Th17/Treg cell imbalance in RA patients [24].
Targeting the Th17 pathway in autoimmune diseases such as RA is very promising [29]. However, factors promoting Th17 differentiation are poorly understood. Since specific intestinal microbiota greatly promotes Th17 differentiation in intestinal mucosa, exposure to (deranged) intestinal microbiota may be a critical factor in autoimmune arthritis.

\section{Intestinal Microbiota and Regulation of the Immune Response}

Large numbers of commensal microorganisms inhabit the gastrointestinal tract of mammals. It has been shown that this commensal microbiota is essential for a proper development of the immune system, as GF mice possess an underdeveloped mucosal immune system [30]. GF mice have decreased numbers of lamina propria $\mathrm{CD} 4^{+}$cells, hypoplastic Peyer's patches, and greatly reduced immunoglobulin A (IgA) producing plasma cells $[30,31]$. In addition, also spleen and lymph nodes are underdeveloped in GF mice, as they contain poorly formed $\mathrm{B}$ and $\mathrm{T}$ cell zones [30]. Introduction of Bacteroides fragilis into GF mice has been shown to induce correct development of the immune system [32].

Ivanov et al. showed that the introduction of SFB in GF mice resulted in an increase of Th17 cells in the intestinal lamina propria [33]. In the murine gut, the presence of SFB has been shown to promote the development of Th17mediated autoimmune diseases such as experimental autoimmune encephalomyelitis (EAE), colitis, and arthritis [3436]. Colonization of mice with $B$. fragilis, a human commensal, induces Tregs and prevents development of 2,4,6trinitrobenzene sulfonic acid- (TNBS-) induced colitis [37]. In addition, oral treatment of mice with polysaccharide $A$ (PSA), a molecule expressed by B. fragilis, induced IL-10 producing Tregs and protected against EAE [38]. Another study showed that colonization of mice with microbiota belonging to the Clostridium species also resulted in the induction of Tregs [39]. In addition, colonization of young mice with mix of Clostridium species resulted in resistance to dextran sodium sulfate- (DSS-) induced colitis [39]. These studies suggest that intestinal microbiota plays an important role in maintaining the balance between pro- and anti-inflammatory $\mathrm{T}$ cells, thereby preserving intestinal homeostasis.

A recent study elegantly demonstrated the specific labeling and tracking of intestinal leukocytes [40]. It was shown 
that intestinal leukocytes migrate to and from the intestine at steady state [40]. In addition, the migration of intestinal Th17 cells in arthritic $\mathrm{K} / \mathrm{BxN}$ mice was studied and showed that gut derived Th17 cells end up in the spleen [40]. The fraction of gut-derived Th17 cells present in the spleen correlated with serum level of pathogenic auto antibodies [40]. This is the first study which shows that gut-derived Th17 cells can contribute to autoimmune arthritis [40].

Taken together, it is conceivable that a disturbed balance in the composition of microbiota, the so-called dysbiosis, could result in disruption of intestinal and systemic immune homeostasis. A link between intestinal microbiota and autoimmune deficiencies such as RA seems therefore plausible [41].

\section{Rheumatoid Arthritis and Microbiota}

Treatment with tetracycline antibiotics, in particular minocycline, was shown to significantly reduce disease activity in seropositive RA patients with disease duration of $<1$ year [42]. Moreover, the commonly used DMARD sulfasalazine is known to have both anti-inflammatory and antimicrobial properties [43]. Using a small set of oligonucleotide probes detecting broad groups of bacteria, intestinal microbiota of RA patients was found different from that of fibromyalgia (FM) patients [44]. The authors did not include healthy control subjects in the study; however a group of patients with FM, having a comparable age and sex distribution and receiving similar treatment with NSAIDS drugs, were included as controls. This study showed that RA patients had significantly less bifidobacteria species, bacteria of the Bacteroides-Porphyromonas-Prevotella group, Bacteroides fragilis subgroup, and the Eubacterium rectal-Clostridium coccoides group, when compared to FM patients [44].

A recent study using 454 pyrosequencing of $16 \mathrm{~S}$ rRNA of intestinal microbiota in stool samples found a strong correlation between the presence of Prevotella copri with disease in new-onset untreated RA patients [45]. Abundance of $P$. copri in this study was inversely correlated with the presence of HLA-DRB-1 risk alleles, suggesting requirement of intestinal microbial signals in the absence of genetic predisposition factors for one to develop the disease. Another study demonstrated that fecal microbiota of RA patients contained significantly more Lactobacilli compared to healthy controls [46]. Altogether, the efficacy of oral antibiotic treatment and recent findings on disturbed composition of intestinal microbiota in early RA supports the involvement of microbiota in the development of RA.

\section{Experimental Evidence on the Role of Commensal Microbiota in Arthritis}

The critical role of commensal microbiota in the development of arthritis has been shown in at least three spontaneous autoimmune models of arthritis. These studies showed that spontaneous disease in mice with $\mathrm{T}$ cell-activating genetic modifications is greatly diminished under germ-free (GF) or specified pathogen-free (SPF) conditions [13, 36, 47].
Another study showed that oral treatment with enrofloxacin, a broad-spectrum antibiotic, exacerbates collagen induced arthritis (CIA) in mice by influencing production of a number of proinflammatory cytokines such as IL- 6 and IL-17 [48].

IL-1 receptor antagonist (IL-1Ra) deficient mice spontaneously develop autoimmune arthritis due to excessive IL-1 signaling [49]. Development of autoimmune arthritis in this mouse model is dependent on microbial flora, as arthritis was strongly attenuated in GF IL-1Ra ${ }^{-/-}$mice [13]. Colonization with Lactobacillus bifidus resulted in arthritis with incidence and severity scores comparable to those observed in conventionally housed mice [13]. The GF status $\mathrm{IL}-1 \mathrm{Ra}^{-/-}$mice resulted in a notable decrease in IL-17 and IL$1 \beta$ production by splenocytes upon CD 3 as well as TLR 2 and TLR4 stimulation, suggesting abolishment of Th17 differentiation [13].

SKG mice have a mutation in the gene encoding an $\mathrm{SH} 2$ domain of ZAP-70, a signal transduction molecule in T cells. The aberrant ZAP-70 is thought to change the thresholds of $\mathrm{T}$ cells to thymic selection, which results in the positive selection of otherwise negatively selected autoimmunity $\mathrm{T}$ cells [50]. SKG mice develop chronic autoimmune arthritis under conventional conditions; however in strictly controlled SPF environment arthritis failed to develop [47]. Arthritis in SKG mice was shown to be accompanied with high sera levels of IL-6, known to be important in Th17 induction. However, in sera from SKG mice kept in SPF conditions IL-6 was undetectable [47].

$\mathrm{T}$ cells of $\mathrm{K} / \mathrm{BxN}$ mice express a transgenic $\mathrm{T}$ cell receptor which recognizes a self-peptide derive from glucose6-phosphate isomerase (GPI). These autoreactive T cells stimulate GPI-specific B cells to produce high amounts of GPI autoantibodies. Th17 cells seem to be driving arthritis in this model, as neutralization of IL-17 blocked the development in SPF-housed $\mathrm{K} / \mathrm{BxN}$ mice [36]. Intriguingly, GF $\mathrm{K} / \mathrm{BxN}$ mice have an almost complete deficiency of Th17 cells and are protected from severe arthritis [36]. Moreover, oral treatment of $\mathrm{K} / \mathrm{BxN}$ mice with vancomycin or ampicillin inhibited the development of arthritis, while in neomycin-treated mice disease was aggravated [36]. Introduction of segmented filamentous bacteria (SFB), a gut-residing bacteria, in GF $\mathrm{K} / \mathrm{BxN}$ mice resulted in an increase of Thl7 cells in the lamina propria and in onset of arthritis [36]. These results suggest that certain intestinal microbiota is able to trigger an imbalance in the $\mathrm{T}$ cell response which leads to the development of autoimmune arthritis in a genetically predisposed host.

\section{TLR-Mediated Interactions between Bacterial Antigens and the Immune System}

Although the mechanism by which commensal intestinal microbiota triggers the development of autoimmune diseases remains poorly understood to date, TLRs are most likely involved. TLRs recognize microbe-associated molecular patterns (MAMPs), which are shared by many microorganisms [51]. Each TLR recognizes certain MAMPs; for 


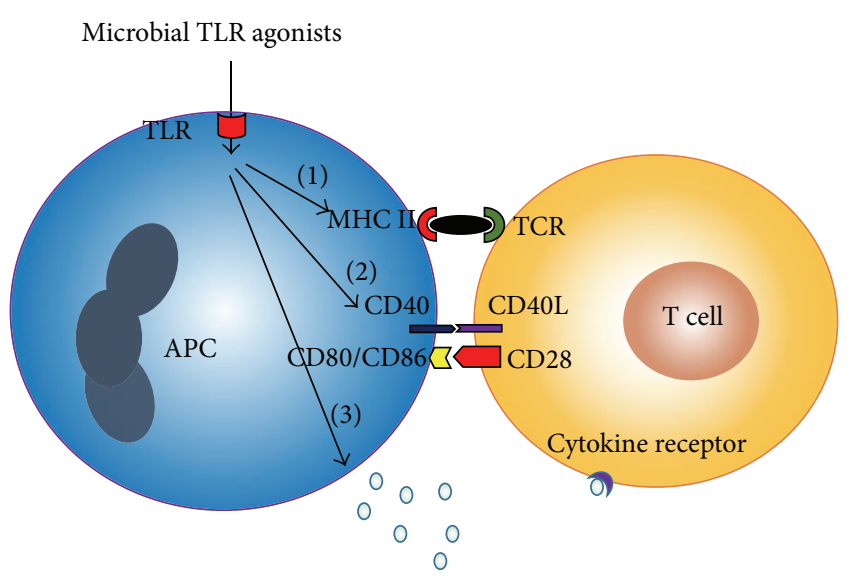

FIGURE 2: Toll-like receptor (TLR) activation on antigen presenting cells (APCs) enhances the antigenic signal to T cells. TLR activation induces the upregulation of MHC II (1), costimulatory molecules such as CD80, CD86, and CD40 (2), and release of cytokines (3).

instance, TLR2, TLR4, TLR5, and TLR9 recognize peptidoglycans, lipopolysaccharides (LPS), flagellin, and unmethylated $\mathrm{CpG}$ motifs in bacterial DNA, respectively [52]. TLRs are expressed by a number of immune cells, including dendritic cells (DCs), macrophages, neutrophils, T cells, and $\mathrm{B}$ cells, but TLRs have also been found on resident cells, such as epithelial and endothelial cells [53].

Antigen presenting cells (APCs) such as DCs and macrophages are known to express TLRs, and activation of TLRs induces the upregulation of MHC class II molecules and thereby may substantially influence the strength of the antigenic signal to $\mathrm{T}$ cells in the "immunological synapse" [54] (Figure 2). Furthermore, activation of TLRs induces upregulation of costimulatory molecules such as CD80, CD86, and CD40, which provide the second signal for $\mathrm{T}$ cell activation (Figure 2). The third signal for $\mathrm{T}$ cell activation and differentiation, the cytokine environment, is dramatically affected by the type and the extent of TLR activation (Figure 2). For instance, activation of TLR4 and TLR9 is thought to skew T cell differentiation toward the Th1 phenotype through induction of IL-12 production by DCs, whereas TLR2 activation might induce a Th2-biased immune response through production of IL-10 and IL-13 [55-61]. TLR4-induced IL-23 contributes to the expansion and survival of Th17 cells [62]. In addition, conditioned medium from TLR4-stimulated DCs or PBMCs induces Th17 differentiation and IL-17 production, a process potentiated by TGF $\beta[63]$.

In addition to the type of TLR activation, the extent of TLR triggering also seems to determine the type of immune response generated. For instance, it was demonstrated that a high dose of LPS triggers a Th1 response via TLR4 while a low LPS dose results in a Th2 response to an inhaled antigen [64]. Besides APC-mediated T cell activation, some TLRs such as TLR2, 5, and 7/8 are functionally expressed on T cells and directly cause $\mathrm{T}$ cell activation and proliferation upon stimulation [65-67]. Others (TLR3 and TLR9) can enhance survival of activated $\mathrm{CD} 4^{+} \mathrm{T}$ cells [68].
Also joint resident cells are known to functionally express TLRs. RA synovial fibroblasts (RASF) for instance are known to express TLR2, TLR3, TLR4, and TLR9 [69]. Stimulation of RASF with TLR2, TLR3, and TLR4 antigens (peptidoglycans, polyinosinic:polycytidylic acid, and LPS, resp.) results in high production of inflammatory cytokines, MMPs, and vascular endothelial growth factor and results in exacerbation of the Th1 and Th17 response [69].

A study with TLR deficient IL-1Ra ${ }^{-1-}$ mice demonstrated that TLRs play distinct roles in the regulation of the $\mathrm{T}$ cell balance. In this study it was shown that Thl7 differentiation is reduced in TLR4 deficient IL-1Ra ${ }^{-/-}$mice, while TLR2 ${ }^{-/-}$ deficiency results in a shift in $\mathrm{T}$ cell balance from Th 2 and Treg towards Thl cells [13]. In addition, it was shown that IL-1Ra ${ }^{-/-}$ TLR2 ${ }^{-/-}$mice develop a more severe arthritis compared to ${\mathrm{IL}-1 \mathrm{Ra}^{-/-}}^{-\mathrm{TLR}_{2}{ }^{+/+}}$mice [13]. In contrast, TLR4 deficiency in

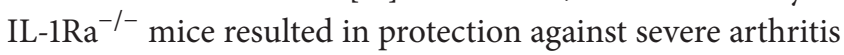
[13]. This study shows that sensing of microbiota by TLRs plays a critical role in maintaining $\mathrm{T}$ cell balance and arthritis development.

\section{Intestinal TLR Triggering}

Commensal bacteria normally do not cross the epithelial barrier. A specific population of CX3CR1 expressing cells in lamina propria has been shown to sample the lumen and interact with commensal bacteria in the lumen [70]. Although, these cells were first identified as DCs, recent studies demonstrated that CX3CR1 expressing cells in the gut are more similar to macrophages than DCs [71, 72]. This is based on the observation that CX3CR1 expressing in the intestinal lamina propria are nonmigratory and cannot prime naïve T cells $[71,72]$. However, another study identified $\mathrm{CD}_{103^{-}} \mathrm{CD} 11 \mathrm{~b}^{+}$DCs which also express CX3CR1; these cells lacked macrophage markers such as F4/80 or CD64 [73]. CX3CR1 expressing cells were thought to be nonmigratory; however a recent study showed that these cells do migrate to mesenteric lymph nodes after antibiotic-induced dysbiosis and in the absence of MyD88 [74]. Despite this finding, it is believed that the $\mathrm{CD}_{11 b^{+}} \mathrm{CD} 103^{+}$classical DC subset is mainly responsible for presentation of bacterial antigen to naïve $\mathrm{CD} 4^{+} \mathrm{T}$ cells and Th17 differentiation in the intestinal lamina propria [74-76]. Stimulation of $\mathrm{CD}_{11 \mathrm{~b}}{ }^{+} \mathrm{CD}_{103}{ }^{+}$cells with flagellin, a TLR5 ligand, resulted in the expression of high amounts of IL-23 [76]. A recent study identified a subset

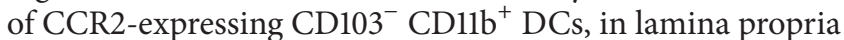
which were able to drive IL-17 production in vitro [77]. These DCs produced IL-12 and IL-23p40, and production of these cytokines increased in response to TLR4 stimulation with LPS. These DCs were found in murine as well as human lamina propria [77].

A recent study showed that luminal bacteria stimulate the recruitment of $\mathrm{CD} 103^{+}$DCs to the epithelium, where these DCs can also sample the lumen [78]. Recruitment of the DC to the epithelium was shown to be depending on chemokines and TLR signaling [78]. Another study showed that TLR5 is highly expressed in DCs in the intestinal mucosa, but not in splenic DCs [79]. This same study showed that TLR $5^{-/-}$ 
mice had increased Treg levels in the intestinal lamina propria, which suggests that TLR5 plays a role in regulating the intestinal Th17/Treg cell balance [79]. Another study demonstrated that TLR5 is expressed by CD $11 c^{\text {hi }}$ CD $11 b^{\text {hi }}$ DCs in lamina propria of mice [80]. These intestinal DCs induce the differentiation of Thl and Thl7 cells in response to flagellin [80]. In addition, TLR9 deficient mice were shown to have more Tregs and reduced Th1 and Th17 cell levels in the intestine [81].

Besides DCs also intestinal epithelial cells (IECs) in the gut are known to express TLRs. TLR 1, 2, 3, 4, 5, and 9 are known to be expressed by IECs in human small intestine, and TLR1-9 have been shown to be present on IEC in the colon [82]. In the mouse TLR1, 2, 3, 4, 5, 9, and 11 have been detected in the small intestine, and in the colon TLR2, 3, 4, and 9 were shown to be present [82]. The expression of TLRs in the gut seems to be regulated by commensal bacteria, as it was shown that the expression of TLR2, 3, 4, and 5 was higher in colonic epithelial cells of specific pathogen-free mice when compared to GF mice [83]. An in vitro study showed that TLR4 and basolateral TLR9 stimulation on IECs drives an inflammatory response [84]. However, apical TLR9 activation resulted in the production and secretion of galectin9, which was shown to support the development of Tregs [85].

TLR signaling on IEC is also important in maintaining the epithelial barrier; for instance, TLR2 activation on epithelial cells protects against barrier disruption by upregulating the expression of zonula occludens, while TLR4 signaling results in increased intestinal permeability through upregulation of membrane protein kinase C activity [86, 87]. Translocation of bacteria across the membrane will result in an inflammatory response in the intestinal lamina propria. It has been hypothesized that intestinal barrier function, in particular the intercellular tight junctions modulated by zonulin among others, may be impaired in autoimmune disease $[88,89]$. However, it is not yet clear whether this is indeed the case in individuals with autoimmune diseases such as RA.

As mentioned before a shift in the Th17/Treg cell balance is considered to be an important aspect of autoimmunity. The studies discussed here indicate an important role of intestinal TLR triggering in shaping the T helper cell subsets. This makes microbial recognition in the intestine interesting in the context of autoimmune diseases such as RA. The studies quoted here are mainly in mice. The role of intestinal TLR triggering in shaping the $\mathrm{T}$ cell response in humans remains mainly unclear and warrants thorough future investigation.

\section{Specific Bacteria Shape the Intestinal Immune Response}

Round et al. showed that polysaccharide A (PSA) of B. fragilis activated TLR2 directly on Tregs, which resulted in activation of these Tregs [90]. However, B. fragilis lacking PSA induces a Th17 response, which suggests that PSA induces an antiinflammatory response through activation of TLR2 [90].
In addition, it was shown that PSA of $B$. fragilis prevents TNBS-induced colitis by inducing IL-10 producing Tregs. However, PSA induced protection was absent in TLR2 ${ }^{-/-}$ mice indicating that TLR2 signaling is required for PSAinduced protection [37]. Another study showed that $B$. fragilis is able to release PSA in outer membrane vesicles which are sensed by DCs through TLR2 resulting in induction of Tregs and IL-10 production [91].

A recent study showed that presentation of SFB antigens by $\mathrm{MHCII}^{+} \mathrm{CD}_{11 c^{+}}$intestinal DCs is required for mucosal Th17 cell differentiation [92]. In MHCII deficient mice, no SFB-induced Th17 differentiation was observed; however recovery of MHCII expression on only CD11c ${ }^{+}$cells was able to rescue Thl7 induction [92]. In mice lacking peripheral lymph nodes and gut-associated lymphoid tissue, SFB induced Thl7 priming was unaffected, suggesting that SFBinduced $\mathrm{T}$ cell priming takes place in the lamina propria [92]. It is likely that the presence of SFB also triggers TLR signaling. SFB encode four types of flagellin, three of which are recognized by TLR5 [93]. In the mouse gut TLR5 is expressed by CD11c ${ }^{\text {hi }} C D 11 b^{\text {hi }}$ DCs in lamina propria which induce the differentiation of Th1 and Th17 cells in response to flagellin [80]. This suggests that SFB skew $\mathrm{T}$ cell differentiation via TLR5 triggering. Involvement of TLRs in bacteria-induced mucosal T cell responses and the subsequent systemic autoimmunity seems therefore plausible.

\section{Conclusion}

Results of multiple studies show that commensal intestinal microbiota affect the Th17/Treg cell balance in the lamina propria and that intestinal Thl7 cells can promote experimental arthritis [33, 36, 37, 39]. In addition, studies with experimental models of arthritis suggest that recognition of intestinal microbiota is required for the onset of autoimmune arthritis $[13,36,47]$. It is likely that TLRs mediate the effects of intestinal microbiota on Th cell differentiation in lamina propria. Multiple studies have shown that TLR activation plays an important role in shaping the intestinal $\mathrm{T}$ cell subsets $[80,84,85,90]$. In addition, the study with IL-1Ra/TLR2 and IL-1Ra/TLR4 double gene deficient mice points toward an important role of these TLRs in T cell mediated autoimmune arthritis [13]. It remained unclear how microbiota-induced Th17 cells exactly contribute to systemic autoimmunity in RA. Cross-reactivity of bacteria-specific Th17 cells to endogenous (joint-derived) antigens is a possible mechanism. Another possibility is that microbiota induced $\mathrm{T}$ cells promote the differentiation of self-reactive Th17 cells by changing the cytokine environment. Migration of intestinal Th17 cells to the joint and subsequent production of proinflammatory mediators is another possible mechanism. A better understanding of these yet unexplored areas and the involvement of TLR triggering by intestinal microbiota in the gut in systemic autoimmunity might offer new perspectives for manipulating the $\mathrm{T}$ cell response in RA patients and may lead to the discovery of new therapeutic targets or even preventive measures. 


\section{Conflict of Interests}

The authors declare that there is no conflict of interests regarding the publication of this paper.

\section{References}

[1] G. S. Firestein, "Evolving concepts of rheumatoid arthritis," Nature, vol. 423, no. 6937, pp. 356-361, 2003.

[2] D. van der Woude and T. W. J. Huizinga, "Translating basic research into clinical rheumatology," Best Practice and Research: Clinical Rheumatology, vol. 22, no. 2, pp. 299-310, 2008.

[3] E. Lubberts, "Th17 cytokines and arthritis," Seminars in Immunopathology, vol. 32, no. 1, pp. 43-53, 2010.

[4] S. K. Lundy, S. Sarkar, L. A. Tesmer, and D. A. Fox, "Cells of the synovium in rheumatoid arthritis. T lymphocytes," Arthritis Research and Therapy, vol. 9, no. 1, article 202, 2007.

[5] S. L. Gaffen, "The role of interleukin-17 in the pathogenesis of rheumatoid arthritis," Current Rheumatology Reports, vol. 11, no. 5, pp. 365-370, 2009.

[6] W. B. van den Berg and P. Miossec, "IL-17 as a future therapeutic target for rheumatoid arthritis," Nature Reviews Rheumatology, vol. 5, no. 10, pp. 549-553, 2009.

[7] L. Klareskog, L. Padyukov, J. Rönnelid, and L. Alfredsson, "Genes, environment and immunity in the development of rheumatoid arthritis," Current Opinion in Immunology, vol. 18, no. 6, pp. 650-655, 2006.

[8] A. K. Andersson, C. Li, and F. M. Brennan, "Recent developments in the immunobiology of rheumatoid arthritis," Arthritis Research and Therapy, vol. 10, no. 2, article 204, 2008.

[9] D. Sugiyama, K. Nishimura, K. Tamaki et al., "Impact of smoking as a risk factor for developing rheumatoid arthritis: a meta-analysis of observational studies," Annals of the Rheumatic Diseases, vol. 69, no. 1, pp. 70-81, 2010.

[10] J. U. Scher, C. Ubeda, M. Equinda et al., "Periodontal disease and the oral microbiota in new-onset rheumatoid arthritis," Arthritis and Rheumatism, vol. 64, no. 10, pp. 3083-3094, 2012.

[11] S. G. de Aquino, S. Abdollahi-Roodsaz, M. I. Koenders et al., "Periodontal pathogens directly promote autoimmune experimental arthritis by inducing a TLR2- and IL-1-Driven Th17 Response," Journal of Immunology, vol. 192, no. 9, pp. 4103-4111, 2014.

[12] J. U. Scher and S. B. Abramson, "The microbiome and rheumatoid arthritis," Nature Reviews Rheumatology, vol. 7, no. 10, pp. 569-578, 2011.

[13] S. Abdollahi-Roodsaz, L. A. B. Joosten, M. I. Koenders et al., "Stimulation of TLR2 and TLR4 differentially skews the balance of T cells in a mouse model of arthritis," The Journal of Clinical Investigation, vol. 118, no. 1, pp. 205-216, 2008.

[14] S. Abdollahi-Roodsaz, M. I. Koenders, B. Walgreen et al., “Tolllike receptor 2 controls acute immune complex-driven arthritis in mice by regulating the inhibitory Fc $\gamma$ receptor IIB," Arthritis and Rheumatism, vol. 65, no. 10, pp. 2583-2593, 2013.

[15] S. Abdollahi-Roodsaz, F. A. J. van de Loo, and W. B. van den Berg, "Trapped in a vicious loop: toll-like receptors sustain the spontaneous cytokine production by rheumatoid synovium," Arthritis Research and Therapy, vol. 13, no. 2, article 105, 2011.

[16] A. Ruyssen-Witrand, A. Constantin, A. Cambon-Thomsen, and M. Thomsen, "New insights into the genetics of immune responses in rheumatoid arthritis," Tissue Antigens, vol. 80, no. 2, pp. 105-118, 2012.
[17] D. Matusevicius, P. Kivisäkk, B. He et al., "Interleukin-17 mRNA expression in blood and CSF mononuclear cells is augmented in multiple sclerosis," Multiple Sclerosis, vol. 5, no. 2, pp. 101-104, 1999.

[18] V. Hölttä, P. Klemetti, H. M. Salo et al., "Interleukin-17 immunity in pediatric crohn disease and ulcerative colitis," Journal of Pediatric Gastroenterology and Nutrition, vol. 57, no. 3, pp. 287292, 2013.

[19] S. Fujino, A. Andoh, S. Bamba et al., "Increased expression of interleukin 17 in inflammatory bowel disease," Gut, vol. 52, no. 1, pp. 65-70, 2003.

[20] M. Veny, M. Esteller, E. Ricart, J. M. Pique, J. Panes, and A. Salas, "Late crohn's disease patients present an increase in peripheral Th17 cells and cytokine production compared with early patients," Alimentary Pharmacology \& Therapeutics, vol. 31, no. 5, pp. 561-572, 2010.

[21] M. Merle Elloso, M. Gomez-Angelats, and A. M. Fourie, "Targeting the th17 pathway in psoriasis," Journal of Leukocyte Biology, vol. 92, no. 6, pp. 1187-1197, 2012.

[22] J. P. van Hamburg, P. S. Asmawidjaja, N. Davelaar et al., "Th17 cells, but not Thl cells, from patients with early rheumatoid arthritis are potent inducers of matrix metalloproteinases and proinflammatory cytokines upon synovial fibroblast interaction, including autocrine interleukin-17A production," Arthritis and Rheumatism, vol. 63, no. 1, pp. 73-83, 2011.

[23] P. Miossec, T. Korn, and V. K. Kuchroo, "Interleukin-17 and type 17 helper T cells," The New England Journal of Medicine, vol. 361, no. 9, pp. 888-898, 2009.

[24] M. Samson, S. Audia, N. Janikashvili et al., "Brief report: inhibition of interleukin-6 function corrects Th17/Treg cell imbalance in patients with rheumatoid arthritis," Arthritis and Rheumatism, vol. 64, no. 8, pp. 2499-2503, 2012.

[25] W. Wang, S. Shao, Z. Jiao, M. Guo, H. Xu, and S. Wang, “The Th17/Treg imbalance and cytokine environment in peripheral blood of patients with rheumatoid arthritis," Rheumatology International, vol. 32, no. 4, pp. 887-893, 2012.

[26] A. Zanin-Zhorov, Y. Ding, S. Kumari et al., "Protein kinase C$\theta$ mediates negative feedback on regulatory T cell function," Science, vol. 328, no. 5976, pp. 372-376, 2010.

[27] E. M. Shevach, R. A. DiPaolo, J. Andersson, D.-M. Zhao, G. L. Stephens, and A. M. Thornton, "The lifestyle of naturally occurring $\mathrm{CD}^{+} \mathrm{CD} 25^{+}$Foxp $3^{+}$regulatory T cells," Immunological Reviews, vol. 212, pp. 60-73, 2006.

[28] T. Korn, E. Bettelli, W. Gao et al., "IL-21 initiates an alternative pathway to induce proinflammatory T H17 cells," Nature, vol. 448, no. 7152, pp. 484-487, 2007.

[29] D. M. Roeleveld, A. E. M. van Nieuwenhuijze, W. B. van den Berg, and M. I. Koenders, "The Th17 pathway as a therapeutic target in rheumatoid arthritis and other autoimmune and inflammatory disorders," BioDrugs, vol. 27, no. 5, pp. 439-452, 2013.

[30] A. J. Macpherson and N. L. Harris, "Interactions between commensal intestinal bacteria and the immune system," Nature Reviews Immunology, vol. 4, no. 6, pp. 478-485, 2004.

[31] A. J. Macpherson, M. B. Geuking, and K. D. McCoy, "Immune responses that adapt the intestinal mucosa to commensal intestinal bacteria," Immunology, vol. 115, no. 2, pp. 153-162, 2005.

[32] S. K. Mazmanian, H. L. Cui, A. O. Tzianabos, and D. L. Kasper, "An immunomodulatory molecule of symbiotic bacteria directs maturation of the host immune system," Cell, vol. 122, no. 1, pp. 107-118, 2005. 
[33] I. I. Ivanov, K. Atarashi, N. Manel et al., "Induction of intestinal Th17 cells by segmented filamentous bacteria," Cell, vol. 139, no. 3, pp. 485-498, 2009.

[34] Y. K. Lee, J. S. Menezes, Y. Umesaki, and S. K. Mazmanian, "Proinflammatory T-cell responses to gut microbiota promote experimental autoimmune encephalomyelitis," Proceedings of the National Academy of Sciences of the United States of America, vol. 108, supplement 1, pp. 4615-4622, 2011.

[35] R. Stepankova, F. Powrie, O. Kofronova et al., "Segmented filamentous bacteria in a defined bacterial cocktail induce intestinal inflammation in SCID mice reconstituted with CD45RBhigh CD $4^{+} \mathrm{T}$ cells," Inflammatory Bowel Diseases, vol. 13, no. 10, pp. 1202-1211, 2007.

[36] H. J. Wu, I. I. Ivanov, J. Darce et al., "Gut-residing segmented filamentous bacteria drive autoimmune arthritis via Thelper 17 cells," Immunity, vol. 32, no. 6, pp. 815-827, 2010.

[37] J. L. Round and S. K. Mazmanian, "Inducible Foxp3+ regulatory T-cell development by a commensal bacterium of the intestinal microbiota," Proceedings of the National Academy of Sciences of the United States of America, vol. 107, no. 27, pp. 12204-12209, 2010.

[38] J. Ochoa-Repáraz, D. W. Mielcarz, Y. Wang et al., "A polysaccharide from the human commensal Bacteroides fragilis protects against CNS demyelinating disease," Mucosal Immunology, vol. 3, no. 5, pp. 487-495, 2010.

[39] K. Atarashi, T. Tanoue, T. Shima et al., "Induction of colonic regulatory T cells by indigenous Clostridium species," Science, vol. 331, no. 6015, pp. 337-341, 2011.

[40] A. M. Morton, E. Sefik, R. Upadhyay, R. Weissleder, C. Benoist, and D. Mathis, "Endoscopic photoconversion reveals unexpectedly broad leukocyte trafficking to and from the gut," Proceedings of the National Academy of Sciences of the United States of America, vol. 111, no. 18, pp. 6696-6701, 2014.

[41] N. Cerf-Bensussan and V. Gaboriau-Routhiau, "The immune system and the gut microbiota: friends or foes?" Nature Reviews Immunology, vol. 10, no. 10, pp. 735-744, 2010.

[42] M. Stone, P. R. Fortin, C. Pacheco-Tena, and R. D. Inman, "Should tetracycline treatment be used more extensively for rheumatoid arthritis? Metaanalysis demonstrates clinical benefit with reduction in disease activity," Journal of Rheumatology, vol. 30, no. 10, pp. 2112-2122, 2003.

[43] P. Hannonen, T. Mottonen, M. Hakola, and M. Oka, "Sulfasalazine in early rheumatoid arthritis: a 48-week doubleblind, prospective, placebo-controlled study," Arthritis and Rheumatism, vol. 36, no. 11, pp. 1501-1509, 1993.

[44] J. Vaahtovuo, E. Munukka, M. Korkeamäki, R. Luukkainen, and P. Toivanen, "Fecal microbiota in early rheumatoid arthritis," Journal of Rheumatology, vol. 35, no. 8, pp. 1500-1505, 2008.

[45] J. U. Scher, A. Sczesnak, R. S. Longman et al., "Expansion of intestinal Prevotella copri correlates with enhanced susceptibility to arthritis," eLife, vol. 2013, no. 2, Article ID e01202, 2013.

[46] X. Liu, Q. Zou, B. Zeng, Y. Fang, and H. Wei, "Analysis of fecal lactobacillus community structure in patients with early rheumatoid arthritis," Current Microbiology, vol. 67, no. 2, pp. 170-176, 2013.

[47] S. Hida, N. N. Miura, Y. Adachi, and N. Ohno, "Cell wall $\beta$ glucan derived from Candida albicans acts as a trigger for autoimmune arthritis in SKG mice," Biological and Pharmaceutical Bulletin, vol. 30, no. 8, pp. 1589-1592, 2007.

[48] I. Dorozyńska, M. Majewska-Szczepanik, and K. Marcińska, "Partial depletion of natural gut flora by antibiotic aggravates collagen induced arthritis (CIA) in mice," Pharmacological Reports, vol. 66, no. 2, pp. 250-255, 2014.

[49] R. Horai, S. Saijo, H. Tanioka et al., "Development of chronic inflammatory arthropathy resembling rheumatoid arthritis in interleukin I receptor antagonist-deficient mice," Journal of Experimental Medicine, vol. 191, no. 2, pp. 313-320, 2000.

[50] N. Sakaguchi, T. Takahashi, H. Hata et al., "Altered thymic Tcell selection due to a mutation of the ZAP-70 gene causes autoimmune arthritis in mice," Nature, vol. 426, no. 6965, pp. 454-460, 2003.

[51] A. Didierlaurent, M. Simonet, and J.-C. Sirard, "Innate and acquired plasticity of the intestinal immune system," Cellular and Molecular Life Sciences, vol. 62, no. 12, pp. 1285-1287, 2005.

[52] H. Kumar, T. Kawai, and S. Akira, "Pathogen recognition by the innate immune system," International Reviews of Immunology, vol. 30, no. 1, pp. 16-34, 2011.

[53] P. A. Hopkins and S. Sriskandan, "Mammalian toll-like receptors: to immunity and beyond," Clinical and Experimental Immunology, vol. 140, no. 3, pp. 395-407, 2005.

[54] C. Pasare and R. Medzhitov, "Toll-like receptors and acquired immunity, Seminars in Immunology, vol. 16, no. 1, pp. 23-26, 2004.

[55] A. M. Krieg, "CpG motifs in bacterial DNA and their immune effects," Annual Review of Immunology, vol. 20, pp. 709-760, 2002.

[56] F. Re and J. L. Strominger, "Toll-like receptor 2 (TLR2) and TLR4 differentially activate human dendritic cells," The Journal of Biological Chemistry, vol. 276, no. 40, pp. 37692-37699, 2001.

[57] C. Reis E Sousa, S. Hieny, T. Scharton-Kersten et al., "In vivo microbial stimulation induces rapid CD40 ligand-independent production of interleukin 12 by dendritic cells and their redistribution to T cell areas," Journal of Experimental Medicine, vol. 186, no. 11, pp. 1819-1829, 1997.

[58] G. Trinchieri, "Interleukin-12 and the regulation of innate resistance and adaptive immunity," Nature Reviews Immunology, vol. 3, no. 2, pp. 133-146, 2003.

[59] S. Agrawal, A. Agrawal, B. Doughty et al., "Cutting edge: different Toll-like receptor agonists instruct dendritic cells to induce distinct Th responses via differential modulation of extracellular signal-regulated kinase-mitogen-activated protein kinase and c-Fos," The Journal of Immunology, vol. 171, no. 10, pp. 4984-4989, 2003.

[60] S. Dillon, A. Agrawal, T. Van Dyke et al., "A Toll-like receptor 2 ligand stimulates Th2 responses in vivo, via induction of extracellular signal-regulated kinase mitogen-activated protein kinase and c-Fos in dendritic cells," Journal of Immunology, vol. 172, no. 8, pp. 4733-4743, 2004.

[61] V. Redecke, H. Häcker, S. K. Datta et al., "Cutting edge: activation of Toll-like receptor 2 induces a Th2 immune response and promotes experimental asthma," Journal of Immunology, vol. 172, no. 5, pp. 2739-2743, 2004.

[62] M. G. Kattah, M. T. Wong, M. D. Yocum, and P. J. Utz, "Cytokines secreted in response to toll-like receptor ligand stimulation modulate differentiation of human Th17 cells," Arthritis and Rheumatism, vol. 58, no. 6, pp. 1619-1629, 2008.

[63] M. Veldhoen, R. J. Hocking, C. J. Atkins, R. M. Locksley, and B. Stockinger, "TGF $\beta$ in the context of an inflammatory cytokine milieu supports de novo differentiation of IL-17-producing $\mathrm{T}$ cells," Immunity, vol. 24, no. 2, pp. 179-189, 2006.

[64] D. A. Piggott, S. C. Eisenbarth, L. Xu et al., "MyD88-dependent induction of allergic Th2 responses to intranasal antigen," The 
Journal of Clinical Investigation, vol. 115, no. 2, pp. 459-467, 2005.

[65] G. Caron, D. Duluc, I. Frémaux et al., "Direct stimulation of human T cells via TLR5 and TLR7/8: Flagellin and R-848 upregulate proliferation and IFN- $\gamma$ production by memory CD4+ T cells," Journal of Immunology, vol. 175, no. 3, pp. 1551-1557, 2005.

[66] D. Kabelitz, "Expression and function of Toll-like receptors in T lymphocytes," Current Opinion in Immunology, vol. 19, no. 1, pp. 39-45, 2007.

[67] M. Komai-Koma, L. Jones, G. S. Ogg, D. Xu, and F. Y. Liew, "TLR2 is expressed activated T cells as a costimulatory receptor," Proceedings of the National Academy of Sciences of the United States of America, vol. 101, no. 9, pp. 3029-3034, 2004.

[68] A. E. Gelman, J. Zhang, Y. Choi, and L. A. Turka, "Tolllike receptor ligands directly promote activated $\mathrm{CD} 4^{+} \mathrm{T}$ cell survival," The Journal of Immunology, vol. 172, no. 10, pp. 60656073, 2004.

[69] F. Hu, Y. L. Li, L. Zheng et al., "Toll-like receptors expressed by synovial fibroblasts perpetuate Th1 and th17 cell responses in rheumatoid arthritis," PLoS ONE, vol. 9, no. 6, Article ID e100266, 2014.

[70] J. H. Niess, S. Brand, X. Gu et al., "CX3CR1-mediated dendritic cell access to the intestinal lumen and bacterial clearance," Science, vol. 307, no. 5707, pp. 254-258, 2005.

[71] C. C. Bain, C. L. Scott, H. Uronen-Hansson et al., "Resident and pro-inflammatory macrophages in the colon represent alternative context-dependent fates of the same Ly6C hi monocyte precursors," Mucosal Immunology, vol. 6, no. 3, pp. 498-510, 2013.

[72] O. Schulz, E. Jaensson, E. K. Persson et al., "Intestinal CD103 ${ }^{+}$, but not $\mathrm{CX}_{3} \mathrm{CR}^{+}$, antigen sampling cells migrate in lymph and serve classical dendritic cell functions," Journal of Experimental Medicine, vol. 206, no. 13, pp. 3101-3114, 2009.

[73] V. Cerovic, S. A. Houston, C. L. Scott et al., "Intestinal CD103dendritic cells migrate in lymph and prime effector T cells," Mucosal Immunology, vol. 6, no. 1, pp. 104-113, 2013.

[74] G. E. Diehl, R. S. Longman, J.-X. Zhang et al., "Microbiota restricts trafficking of bacteria to mesenteric lymph nodes by $\mathrm{CX}_{3} \mathrm{CR}^{\text {hi }}$ cells," Nature, vol. 494, no. 7435, pp. 116-120, 2013.

[75] A. T. Satpathy, C. G. Briseño, J. S. Lee et al., "Notch2-dependent classical dendritic cells orchestrate intestinal immunity to attaching-and-effacing bacterial pathogens," Nature Immunology, vol. 14, no. 9, pp. 937-948, 2013.

[76] M. A. Kinnebrew, C. G. Buffie, G. E. Diehl et al., "Interleukin 23 production by intestinal $\mathrm{CD}_{103}{ }^{+} \mathrm{CD} 1 \mathrm{~b}^{+}$dendritic cells in response to bacterial flagellin enhances mucosal innate immune defense," Immunity, vol. 36, no. 2, pp. 276-287, 2012.

[77] C. L. Scott, C. C. Bain, P. B. Wright et al., "CCR2CD103 intestinal dendritic cells develop from DC-committed precursors and induce interleukin-17 production by T cells," Mucosal Immunology. In press.

[78] J. Farache, I. Koren, I. Milo et al., "Luminal bacteria recruit CD103+ dendritic cells into the intestinal epithelium to sample bacterial antigens for presentation," Immunity, vol. 38, no. 3, pp. 581-595, 2013.

[79] T. Feng, Y. Cong, K. Alexander, and C. O. Elson, "Regulation of Toll-like receptor 5 gene expression and function on mucosal dendritic cells," PLoS ONE, vol. 7, no. 4, Article ID e35918, 2012.

[80] S. Uematsu and S. Akira, "Immune responses of TLR5 $5^{+}$lamina propria dendritic cells in enterobacterial infection," Journal of Gastroenterology, vol. 44, no. 8, pp. 803-811, 2009.
[81] J. A. Hall, N. Bouladoux, C. M. Sun et al., "Commensal DNA limits regulatory $\mathrm{T}$ cell conversion and is a natural adjuvant of intestinal immune responses," Immunity, vol. 29, no. 4, pp. 637649, 2008.

[82] M. T. Abreu, "Toll-like receptor signalling in the intestinal epithelium: how bacterial recognition shapes intestinal function," Nature Reviews Immunology, vol. 10, no. 2, pp. 131-143, 2010.

[83] A. Lundin, C. M. Bok, L. Aronsson et al., "Gut flora, Toll-like receptors and nuclear receptors: a tripartite communication that tunes innate immunity in large intestine," Cellular Microbiology, vol. 10, no. 5, pp. 1093-1103, 2008.

[84] S. de Kivit, E. van Hoffen, N. Korthagen, J. Garssen, and L. E. M. Willemsen, "Apical TLR ligation of intestinal epithelial cells drives a $\mathrm{T}_{h} 1$-polarized regulatory or inflammatory type effector response in vitro," Immunobiology, vol. 216, no. 4, pp. 518-527, 2011.

[85] S. de Kivit, A. D. Kraneveld, L. M. J. Knippels, Y. van Kooyk, J. Garssen, and L. E. M. Willemsen, "Intestinal epitheliumderived galectin- 9 is involved in the immunomodulating effects of nondigestible oligosaccharides," Journal of Innate Immunity, vol. 5, no. 6, pp. 625-638, 2013.

[86] X. Li, C. Wang, J. Nie, D. Lv, T. Wang, and Y. Xu, “Toll-like receptor 4 increases intestinal permeability through up-regulation of membrane PKC activity in alcoholic steatohepatitis," Alcohol, vol. 47, no. 6, pp. 459-465, 2013.

[87] E. Cario, G. Gerken, and D. K. Podolsky, “Toll-like receptor 2 enhances ZO-1-associated intestinal epithelial barrier integrity via protein kinase C," Gastroenterology, vol. 127, no. 1, pp. 224238, 2004.

[88] A. Fasano, "Zonulin and its regulation of intestinal barrier function: The biological door to inflammation, autoimmunity, and cancer," Physiological Reviews, vol. 91, no. 1, pp. 151-175, 2011.

[89] A. Fasano, "Leaky gut and autoimmune diseases," Clinical Reviews in Allergy and Immunology, vol. 42, no. 1, pp. 71-78, 2012.

[90] J. L. Round, S. M. Lee, J. Li et al., "The toll-like receptor 2 pathway establishes colonization by a commensal of the human microbiota," Science, vol. 332, no. 6032, pp. 974-977, 2011.

[91] H. Shen, J. C. Goodall, and J. S. Hill Gaston, "Frequency and phenotype of peripheral blood Th17 cells in ankylosing spondylitis and rheumatoid arthritis," Arthritis and Rheumatism, vol. 60, no. 6, pp. 1647-1656, 2009.

[92] Y. Goto, C. Panea, G. Nakato et al., "Segmented filamentous bacteria antigens presented by intestinal dendritic cells drive mucosal Th17 cell differentiation," Immunity, vol. 40, no. 4, pp. 594-607, 2014.

[93] T. Kuwahara, Y. Ogura, K. Oshima et al., "The lifestyle of the segmented filamentous bacterium: a non-culturable gutassociated immunostimulating microbe inferred by wholegenome sequencing," DNA Research, vol. 18, no. 4, pp. 291-303, 2011. 


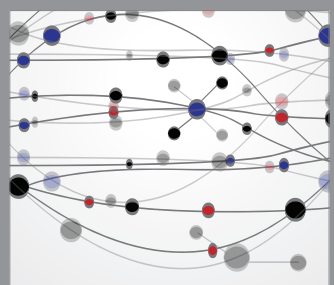

The Scientific World Journal
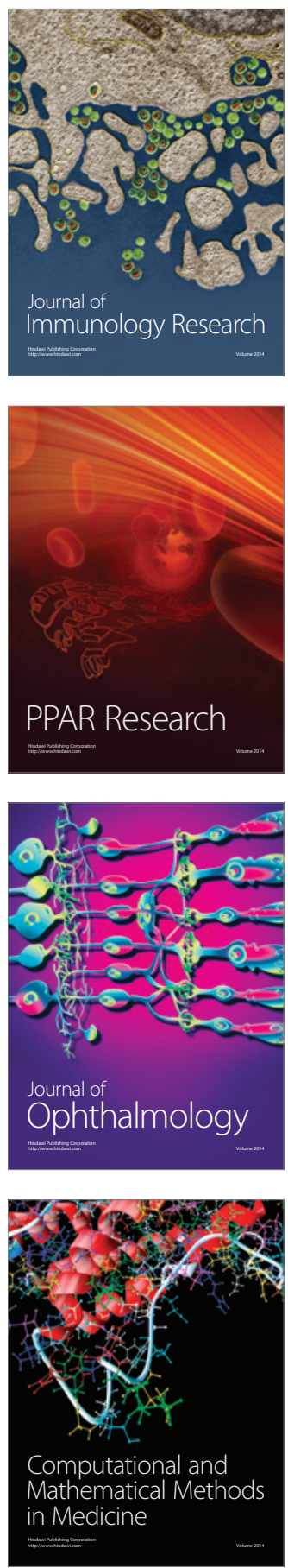

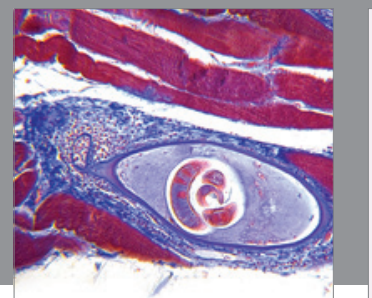

Gastroenterology

Research and Practice
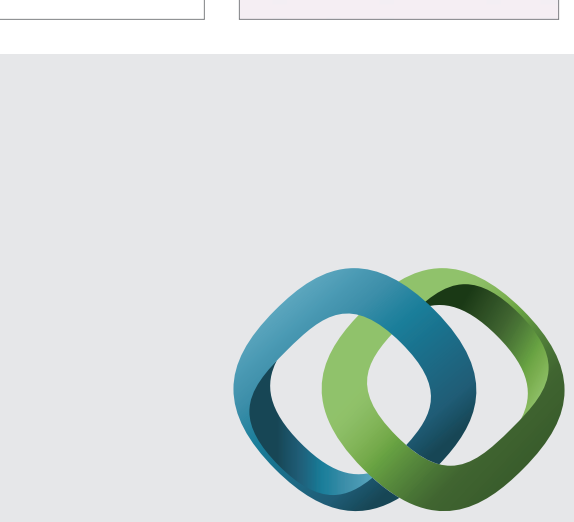

\section{Hindawi}

Submit your manuscripts at

http://www.hindawi.com
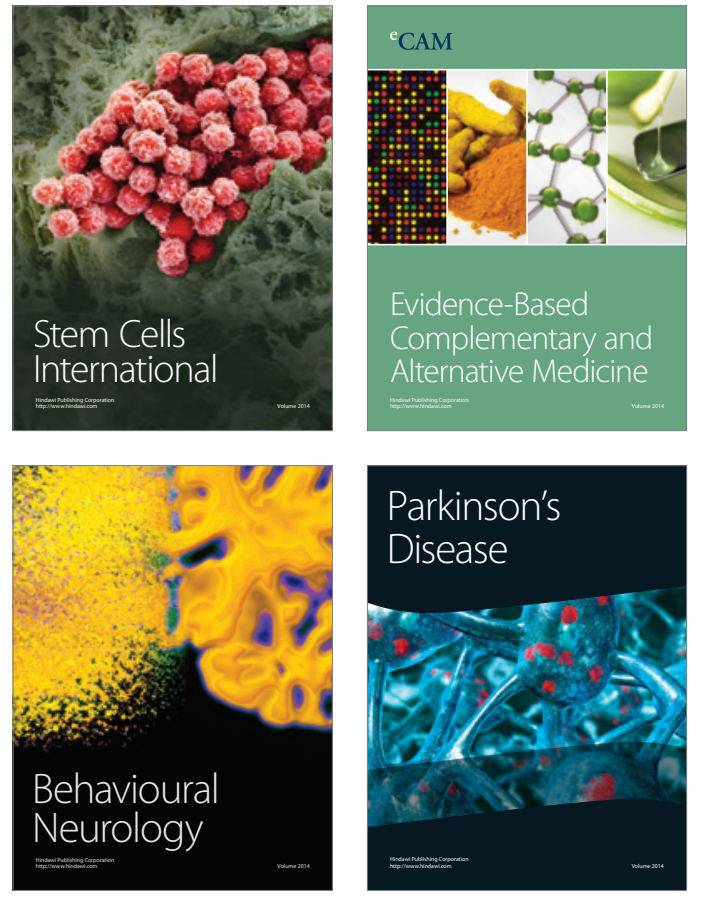
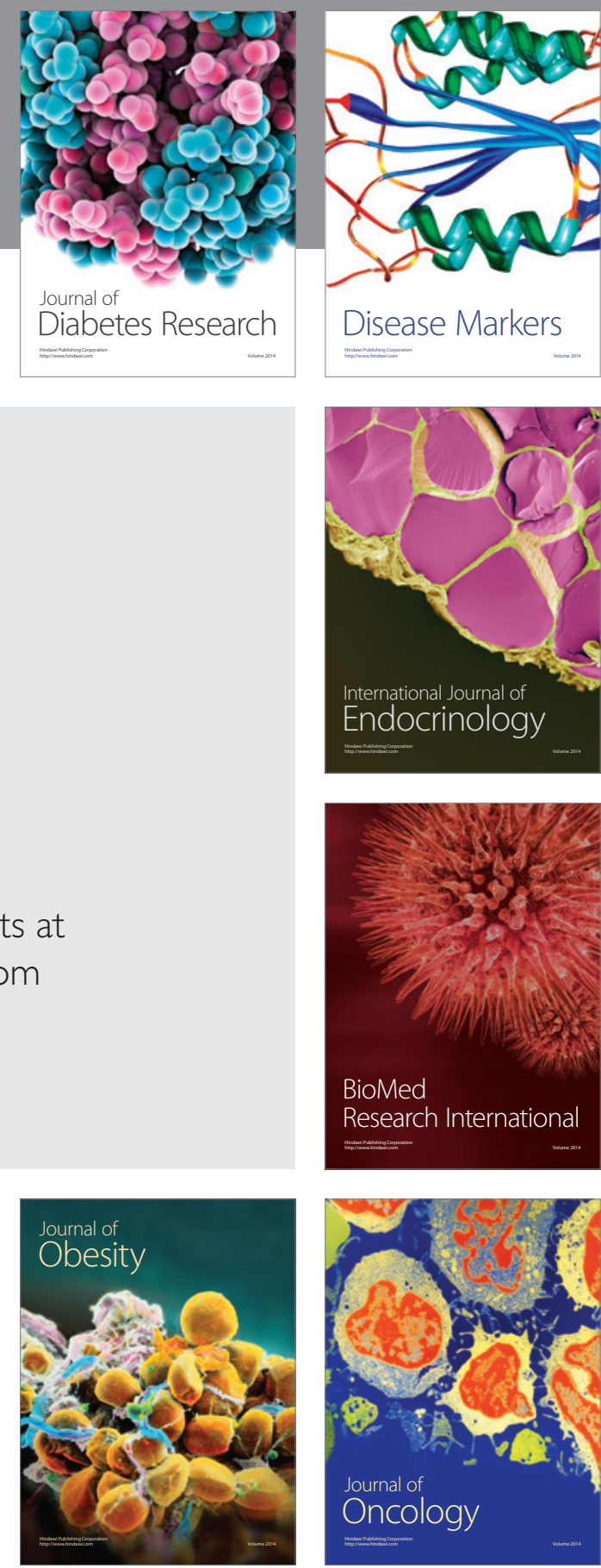

Disease Markers
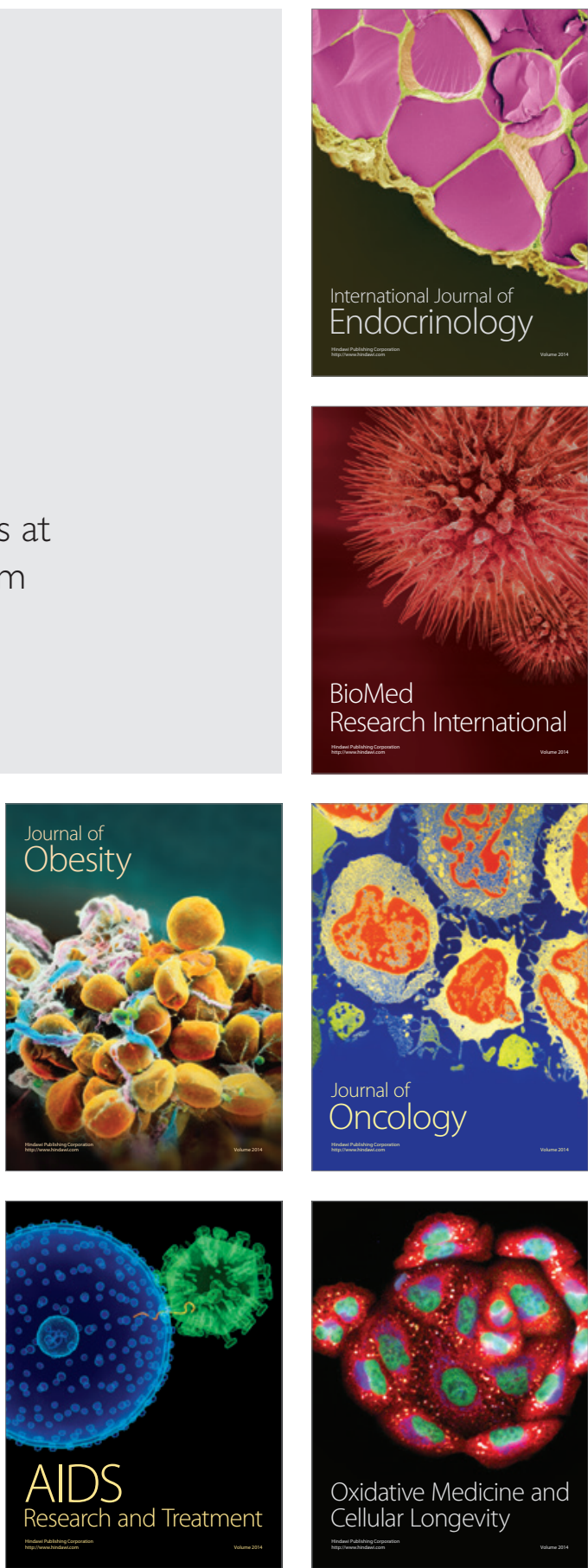